\title{
Polymorphism of the hereditary rhabdovirus sigma in wild populations of its host, Drosophila melanogaster
}

\author{
A Fleuriet \\ Université de Clermont Ferrand II, Laboratoire de Génétique \\ 63177 Aubière Cedex, France
}

(Received 6 July 1990; accepted 22 November 1990)

\begin{abstract}
Summary - In natural populations of Drosophila melanogaster throughout the world a minority of flies are infected by a rhabdovirus, sigma, which is not contagious but is transmitted through gametes. Transmission of the virus by males is a cornerstone for its maintenance in populations. The experiments reported in this paper show that in the wild European populations examined the efficiency of transmission by males is determined mainly by viral genotype. In African populations, genetic coadaptation of both partners can lead to a very low transmission of the virus by males. Evidence is also given of the coexistence in populations of different genotypes of the virus. The situation reported is thus another example of the genetic polymorphism displayed by the sigma virus in the wild.
\end{abstract}

Drosophila melanogaster / sigma virus / polymorphism / vertical transmission

Résumé - Polymorphisme du virus héréditaire sigma dans les populations naturelles de son hôte, Drosophila melanogaster. Dans les populations naturelles de Drosophila melanogaster quelle que soit leur origine géographique, un rhabdovirus, sigma, est habituellement présent dans un petit nombre d'individus; ce virus n'est pas contagieux mais uniquement transmis par les gamètes. Pour sa perpétuation dans les populations, le virus est dépendant de sa transmission par les mâles. Les expériences présentées ici montrent que dans les populations européennes examinées, l'efficacité de transmission par les mâles dépend surtout du génotype viral. Dans les populations africaines le virus est très peu transmis par les mâles, ce qui peut être dî à une coadaptation génétique des 2 partenaires. Différents génotypes du virus coexistent dans les populations. La situation présentée ici constitue donc un autre exemple du polymorphisme génétique du virus sigma.

Drosophila melanogaster / sigma / polymorphisme / transmission verticale

\section{INTRODUCTION}

A rhabdovirus, sigma, is regularly found in natural populations of Drosophila melanogaster around the world (Fleuriet, 1988). Sigma virus is not contagious but is transmitted only through gametes; it is not integrated in the fly chromosomes, but remains in the cytoplasm. Analysis of the Drosophila-sigma system is facilitated by the specific symptom of $\mathrm{CO}_{2}$ sensitivity conferred by the virus upon its host. 
The fact that sigma is not contagious should be stressed, as its maintenance in populations is then comparable to that of other genetic elements which are more efficiently transmitted than a Mendelian allele.

Fly populations are also polymorphic for 2 alleles, $O$ and $P$, of a gene for resistance to the virus, the $\operatorname{ref}(2) P$ locus (Gay, 1978). The $P$ allele, which is in the minority in the wild, interferes with viral multiplication and transmission. Two viral types coexist in populations: type I, which is very sensitive to the $P$ allele and type II, which is more resistant (Fleuriet, 1988).

One important characteristic of the sigma virus is that it is vertically transmitted not only by females but also by males; some level of male transmission, in addition to the very efficient transmission through the female gametes is the cornerstone for its maintenance in populations. This parameter has been shown to vary over space (Fleuriet, 1986) and time (Fleuriet, 1990). The experiments reported in this paper were aimed at establishing whether the value of this parameter was mainly determined by fly or virus genotype (or both). For this purpose, viral clones differing in the efficiency with which they were originally transmitted by males were transferred into flies of identical genotype. Measurement of male transmission would then indicate which was the main component of its value. These data also illustrate the polymorphism of wild sigma virus clones and give another example of coadapted genotypes in a host parasite system (Carton, 1986).

\section{MATERIALS AND METHODS}

\section{Culture conditions}

Flies were maintained on axenic food (David, 1959) at $20^{\circ} \mathrm{C}$ under natural light conditions.

\section{Frequency of infected flies}

The $\mathrm{CO}_{2}$ test was used to measure the frequency of infected flies as described by Plus (1954).

\section{Standard strains}

$B 2^{\prime}$ was a wild strain derived from a sample collected in Brittany in 1972. The $X M_{5} B / Y, I I M_{5} / C y, I I I M 5 / D c x F$ males used in each experiment were the progeny of a cross between $X / Y, C y / P m, D c x F / S b$ males and $M_{5} B$ Birmingham females. These 2 strains carried a wild type fourth chromosome. The $X M_{5} B, I I C y$ and IIIDcxF chromosomes were used to suppress crossing over because of the inversions they carried. $O / O$ and $P / P$ standard strains were also used (Fleuriet, 1980).

\section{Wild populations: origin of viral clones}

In the first experiment carried out in 1987, viral clones were carried by infected lines isolated from samples collected in the Languedoc (Southern France) in September 
1986 (Fleuriet et al, 1990). In the second experiment carried out in 1988, infected lines derived from samples collected in September 1987 at Biziat (northeastern France), Tübingen (Germany, Pr Sperlich), Andasibé and Mandraka (Madagascar, Pr David). In the third experiment carried out in 1989, infected lines derived from samples collected in September 1988 at Biziat, Ménétréol (central France) and Gilroy (California, Pr Ayala). Andasibé 1987 was again used.

\section{Measurement of the transmission of the virus by males}

The tested lines were "stabilized" lines isolated from samples collected in the wild (Fleuriet, 1990). Each line was assumed to carry one viral clone only (since most germ line cells are infected by one viral particle only). In a stabilized line, each female transmits the virus and the stabilized condition to its whole progeny (Fleuriet, 1988). Each male transmits the virus to only a proportion of its progeny. The "valence" of a stabilized male corresponds to the frequency of infected flies in its offspring (Fleuriet, 1988). In these experiments, valences were measured in the progeny of individual males crossed with uninfected $O / O$ females of a reference strain. (Valences were also measured in the progeny of males crossed with uninfected $P / P$ females for determination of the viral type (Fleuriet, 1988), but the results will not be presented in detail in this paper.)

\section{Protocols}

\section{Experiment 1}

The protocol used in this experiment is as described in figure 1, and is based on the fact that stabilized females transmit the virus and the stabilized condition to their entire progeny. The experiment was carried out until generation 4 only.

\section{Experiment 2}

The protocol is presented in figure 1, and is exactly the same as in Experiment I, with 2 additional generations, which resulted in each viral clone again being in the original genotype of the corresponding line.

\section{Experiment 3}

The protocol for this experiment is given in figure 5 .

\section{RESULTS AND DISCUSSION}

\section{Experiment 1}

The valence of a male is the frequency of infected flies in its progeny. The average value of valences in a line is characteristic of that line and is transmitted over generations. Previous observations have shown that, in natural populations, valences can vary over space (Fleuriet, 1986) and time (Fleuriet, 1990). This experiment was designed to determine whether the efficiency with which sigma 
virus was transmitted by males in a line depended mainly on fly or virus genotype (or both).

For this purpose, the viral clones perpetuated in different lines with high or low valences were transferred into isogenic flies. If valence was mainly determined by fly genotype, it would then become identical for all the viral clones, whatever its initial value may have been. If valence was mainly of viral origin, the differences observed between lines would persist, even after standardization of fly genotype.

The protocol used in this experiment is described in figure 1. Thirteen lines were tested each of them bringing its viral clone. At the end of the experiment (generation 4), the 13 viral clones perpetuated in these lines were carried by 13 lines whose genotype had been made identical. The genotype chosen was that of a strain of wild origin kept in the laboratory since 1972 ( $B_{2^{\prime}}$ strain).

It would of course have been easier to inject viral clones into flies of the chosen genotype. This was not done, since it is well known that the viral types selected for are not the same after injection or hereditary transmission (unpublished results). The intention was to remain as close as possible to viral types found in wild populations. Viral clones were thus only transferred through maternal transmission. This was also the reason why each experiment was performed on recently collected viral samples (collected less than 6 months ago).

Valences were measured on $G_{4}$ males in which the $B_{2^{\prime}}$ genotype had been reconstituted. They were also measured on $G_{3}$ males of the same genotype as those used to produce generation 4 (fig 1 ). The reason why these $G_{3}$ males were also examined was that it was not certain, a priori, that enough $G_{4}$ males of the chosen genotype would be obtained at the end of the experiment, and that many of them would not be sterile. $G_{3}$ males did not present the entire $B_{2^{\prime}}$ genotype, but only half of it for the 3 main chromosomes (the fourth chromosome, which carries very few genes, was not controlled in these experiments). The important point is that they were nevertheless of identical genotype.

Results are presented in figure 2. In many cases, data were too scarce to allow precise quantitative comparison. Some unambiguous conclusions can nevertheless be drawn from a qualitative analysis of the results. Three series of measurements were performed on each line (see fig 2). Lines were distributed according to the original value of valence. It appears clearly that in graphs $\mathrm{c}$, where genotypes have been standardized for all the infected lines, valences are not identical in the different lines; when valence is high in the line (graph a), it remains high in $B_{2^{\prime}}$ genotype $(\mathrm{J}, \mathrm{K}, \mathrm{L}, \mathrm{M})$. When it is weak or heterogeneous, (A, B, C, D, E, F, G, H, I), it remains so in the $B_{2}$ genotype. This indicates that the valence value observed in a line is mainly of viral origin since it keeps its original value even after the fly genotype has been made uniform.

But another observation confirms what has long been known (unpublished results): some fly genotypes can modify valence. In graph b, (ie on $G_{3}$ males of $M_{5} / C y D c x F$ genotype), for lines presenting weak values, valences are systematically higher than in graphs a and c. It is clear that in this particular genotype, viral clones are better transmitted than in the original genotype of the line. It is to be noted that this genotype is artificial and does not exist in the wild, contrarily to original or $B 2^{\prime}$ genotypes, all of wild origin. It indicates that, on the average, these viral clones might be more efficiently transmitted than they are, but are somewhat 


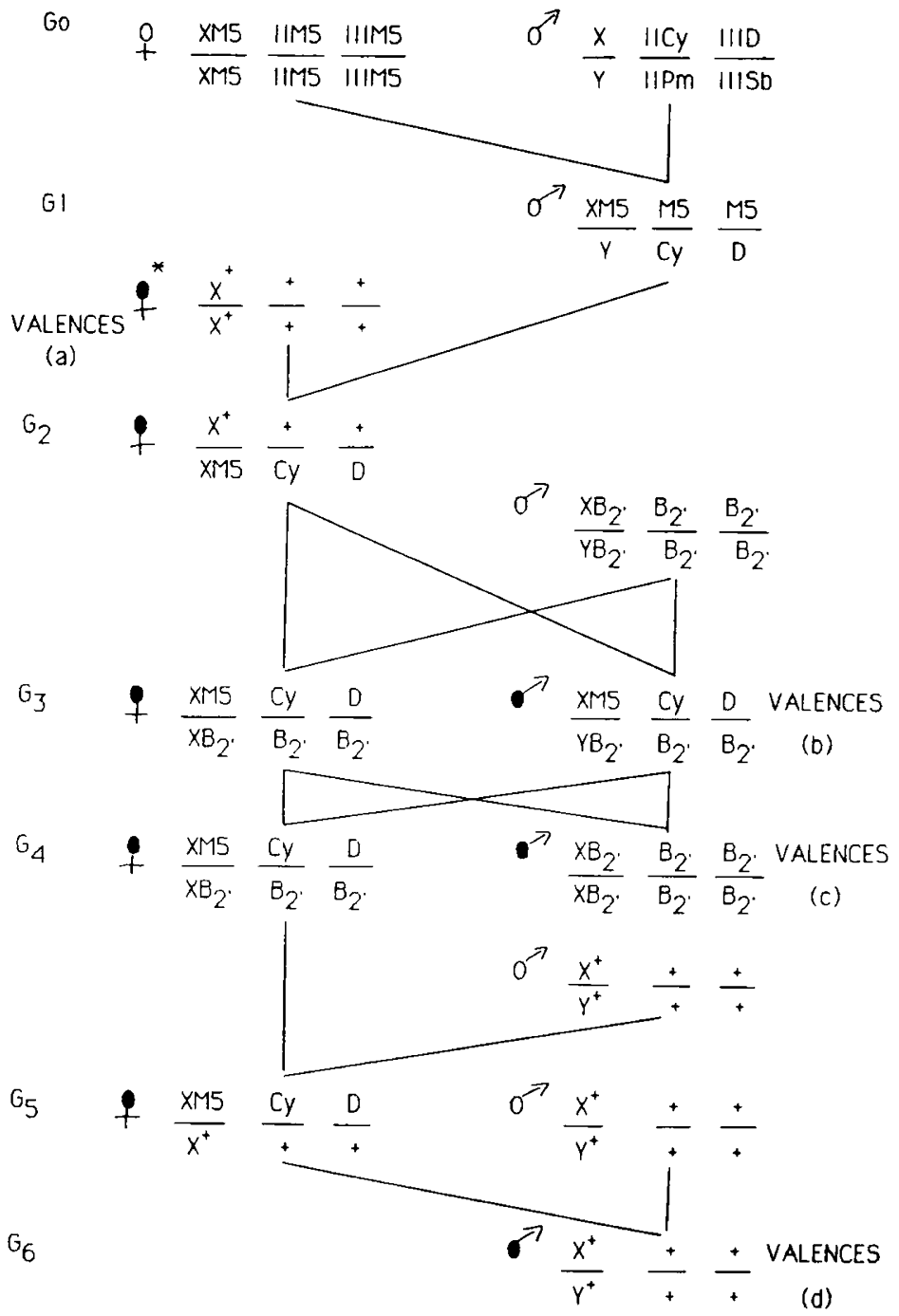

Fig 1. Protocol used in Experiments 1 and 2. Experiment 1: the same protocol, carried out till generation 4, was used for each of the 13 lines examined. Experiment 2: the same protocol, carried out till generation 6, was used for each of the 10 lines examined. $M_{5}$ : chromosome originating in the $M_{5} B$ Birmingham strain; $B_{2^{\prime}}$ : chromosome originating in the $B_{2}$ strain; \pm : chromosome originating in the wild infected line examined. Only $X_{5}, I I C y$, and $I I I D c x F$ chromosomes carry inversions and are crossing over inhibitors. Chromosome IV was not controlled in the experiments. $Q$ o uninfected flies: $q$ infected flies; ${ }^{*}$ females of the infected line examined, through which the viral clone tested was introduced into the experiment at generation 1 . The viral clone was then transmitted through maternal inheritance. Male valence: frequency of infected flies in its progeny after crossing with an uninfected female (of $O / O$ genotype in these experiments). Three valence measurements were performed in Experiment $1(a, b, c$ : see fig 2) and 4 in Experiment 2 $(a, b, c, d$ : see figs 3 and 4$)$. Graph $a$ : valences measured on brothers of $Q^{*}$ (valences in the original line before the experiment). Graph $b$ : valence of $M_{5} C y D / B_{2}$ ' males carrying the viral clone tested. Graph $c$ : valence of $B_{2}$ ' males (reconstituted $B_{2}$ genotype) carrying the viral clone tested. Graph $d$ : valences of males, carrying the viral clone tested and with reconstituted original genotype. 

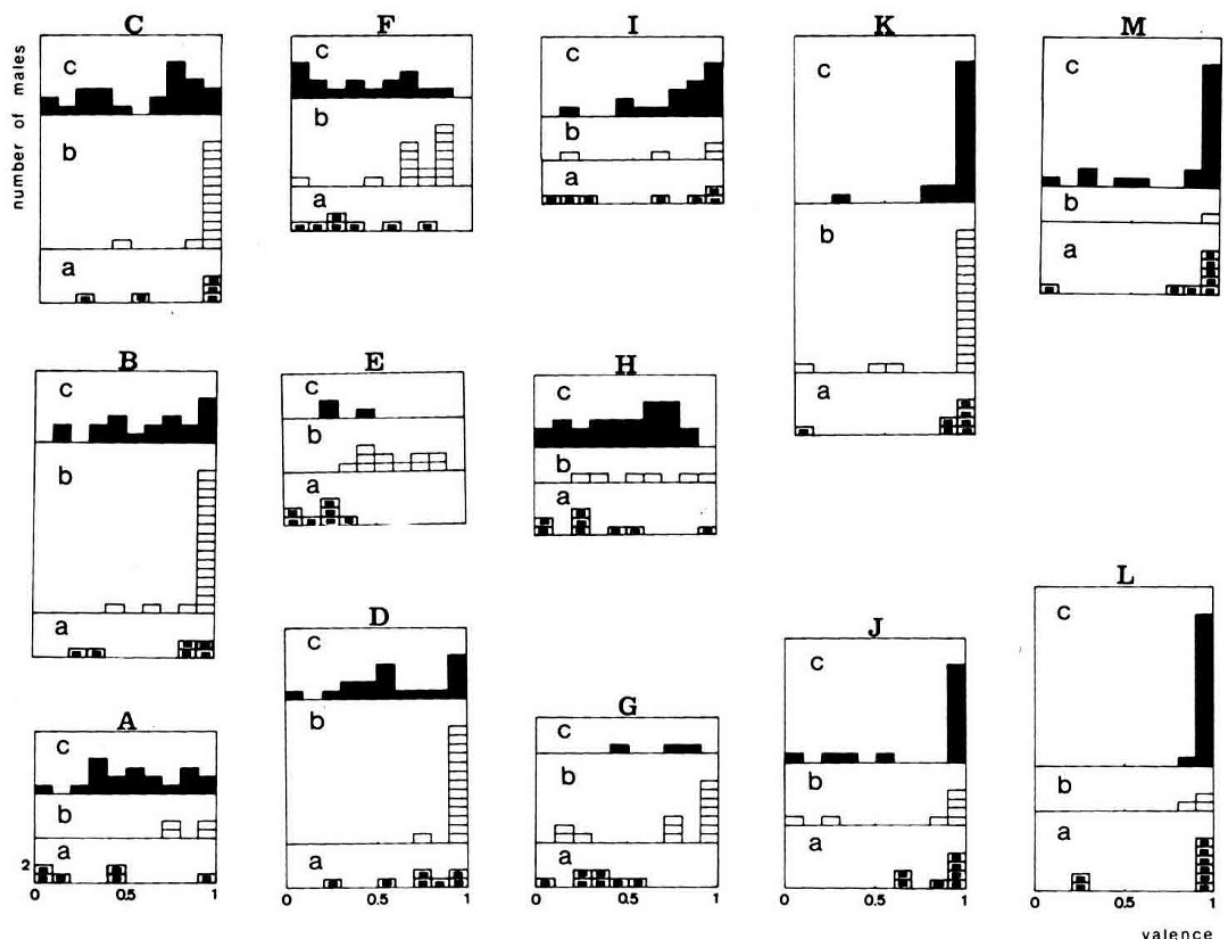

Fig 2. Measurement of valences in Experiment 1 (see protocol in figure 1). $X$ axis: valences of individual males ( $i e$ frequency of infected flies in their progeny) when crossed with uninfected $O / O$ females; $Y$ axis: No of analyzed males. Graph a (black dots): valences in the original line just before the experiment. Graph $b$ (white): valences of $G_{3}$ males. Graph $c$ (black): valences of $G_{4}$ males. 13 lines were examined (see Materials and Methods): A: Ventenac 97; B: Crespian 67; C: Ferrals 41; D: Rivesaltes 22; E: Bages 148; F: Ales 5; G: Gigean 132; H: Aniane 81; I: Portinagnes 4; J: Ferrals 39; K: Salses 85; L: Tuchan 156; M: Rivesaltes 38 .

restricted in the wild by their host genotype. These observations are true for type I (with reference to the $P$ allele) viral clones $(\mathrm{A}, \mathrm{B}, \mathrm{C}, \mathrm{D}, \mathrm{J})$, as for type II viral clones (E, F, G, H, I, K, L, M).

Measuring in each case valences with a $P / P$ reference strain also shows, as was expected, that modifying the fly genetic background does not change the sensitivity of viral clones to the $\operatorname{ref}(2) P$ locus, which is a viral characteristic (data not presented here).

\section{Experiment 2}

The aim was the same as that of first experiment, with an additional control. An inconvenience of the protocol used, which would not be encountered in injection experiments, is that viral clones are transferred for a few generations into various fly genotypes. They can eventually be genetically modified. This would not change the interpretation of Experiment 1, the results of which are clear enough, but it 
might explain the difference observed between graphs $a$ and $c$ in figure $2 \mathrm{G}$ for example. As a control, the original genotype of each line was thus reconstituted at the end of the experiment and male valences were then measured again. The protocol is presented in figure 1. It is exactly the same as in Experiment 1, with 2 additional generations, which result in each viral clone again being in the original genotype of the corresponding line. Four measurements of valences are performed. For populations of European origin ( 8 lines), results are presented in figure 3 . As in figure 2 , lines are distributed according to their valence, weak or strong. Most of the results are quite similar to those of Experiment 1 . Unfortunately, only one viral clone among those available was very efficiently transmitted (graph $\mathrm{H}$ ). Nevertheless, a comparison of graphs $\mathrm{Hc}, \mathrm{Ac}$ and $\mathrm{Bc}$, for example, for which original valences were unambiguously different, clearly shows that valences remain different once fly genotype has been standardized.
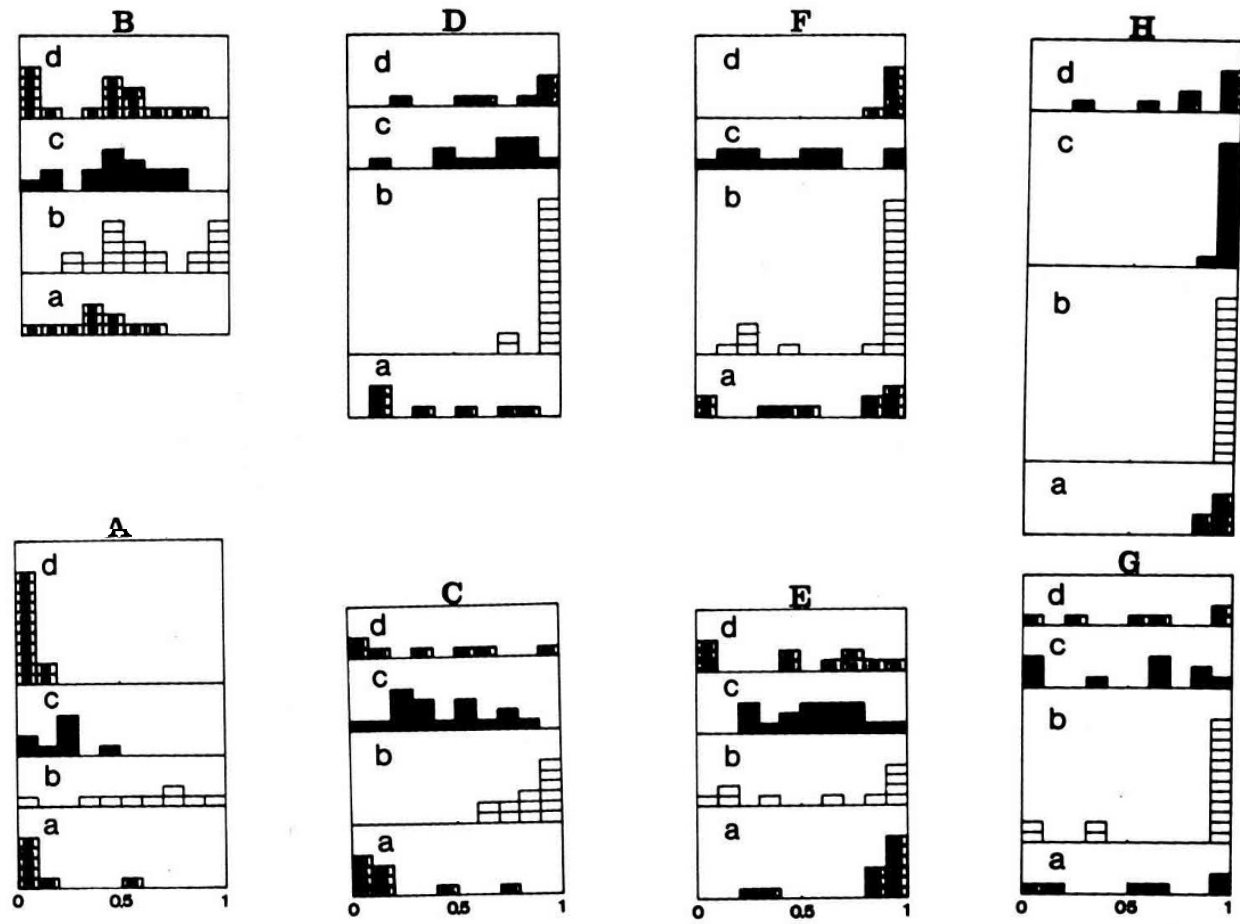

Fig 3. Measurement of valences in Experiment 2 (8 infected lines of European origin); protocol as in figure 1, symbols as in figure 2. Graph a (black dots): valences in the original line just before the experiment. Graph $b$ (white): valences of $G_{3}$ males. Graph $c$ (black): valences of $G_{4}$ males. Graph $d$ (black dots): valences of $G_{6}$ males (reconstituted original genotype) carrying the viral clone examined in each line. Origin of the 8 infected lines examined (see Materials and Methods): A: Biziat 11; B: Tübingen 177; C: Biziat 48; D: Biziat 22; E: Biziat 8; F: Biziat 36; G: Biziat 50; H: Tübingen 39.

A few differences may be noted. In graphs Dc and Ec, ( $B_{2^{\prime}}$ genotype), the values observed differ from those observed on graphs $a$ (original genotype). This 
may be explained by a variation of viral genotype: the values observed on $d$, after reconstitution of the original genotype also differ from $a$, but in each case, $c$ and $d$ are very close to each other. For $\mathrm{F}$, on the contrary, the results observed in $c$ are much more similar to those in $a$ than those observed in $d, 2$ generations later, when the original genotype has been reconstituted.

The results of Experiment 2 confirm those of Experiment 1: male valence in these lines is not determined by fly genotype but is mainly of viral origin. This conclusion might be of general significance, since the European populations examined in Experiment 2 differ from those of Experiment 1 in their geographical origin and also their evolution in the wild (Fleuriet, 1990). These results confirm previous observations made on natural populations (Fleuriet et al, 1990). As in Experiment 1 , viral clones are better transmitted by males of $M_{5} / C y D c x F$ genotype (graphs b).
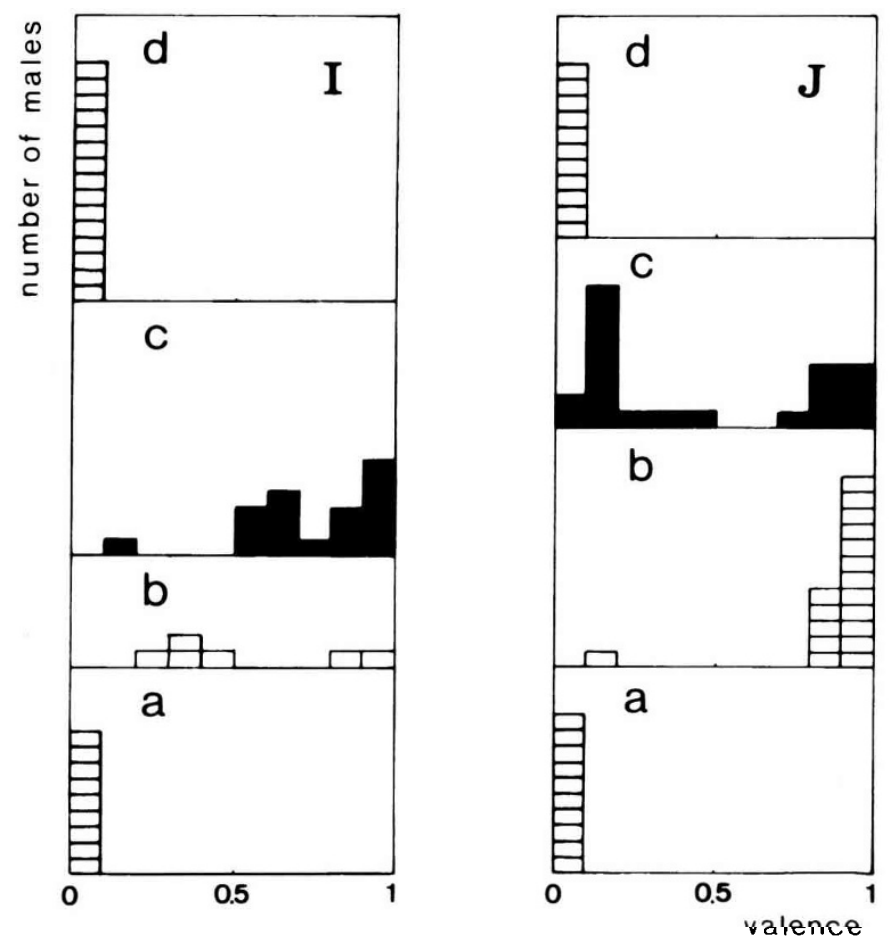

Fig 4. Measurement of valences in Experiment 2 (2 lines of African origin); protocol as in figure 1, symbols as in figure 3. Origin of the 2 infected lines examined: I: Andasibé; $\mathrm{J}$ : Mandraka.

The results observed with 2 populations of African origin are presented in figure 4. It has previously been shown (Fleuriet, 1986) that in African populations, valences are very low and the sigma virus is practically not transmitted by males ( $<10 \%$ of their progeny). The purpose of this analysis was to determine whether this low transmission is of viral or fly origin. The protocol used was that presented in figure 1. It appears clearly that, once viral clones are transferred into another fly 
genotype (graphs $b$ and $c$ ) they are much better transmitted. When put back into the original genotype (graph $d$ ), valence regains its original value, which excludes selection of more efficient viral types during the experiment. It thus appears that in these populations, transmission of the virus is strongly restricted by the host. The clone collected at Andasibé can be very efficiently transmitted by males of another genotype. The progeny of the clone collected at Mandraka appears to be heterogeneous: some clones are very efficiently transmitted, while others are only a little better transmitted in $B_{2^{\prime}}$ genotype. It is not possible to determine clearly whether this reflects a segregation of viral or $B_{2^{\prime}}$ genes. A few other examples are known where transmission of viruses is restricted in their host vectors (Hardy et al, 1983).

In the presence of the $P$ allele, transmission of the virus by males remains nil as it was in the original genotype, since Andasibé and Mandraka clones are type I clones (data not presented here).

The genetic determinism of transmission restriction in flies is not known. The protocol used would not discriminate between the effect of one locus or of various loci on the 3 main chromosomes. This effect cannot be due to the $\operatorname{ref}(2) P^{p}$ allele: firstly, its effect upon viral clones is not the same and secondly, $P$ allele frequency in these populations is very low (below 0.05) as it is in other African populations (Fleuriet, 1986). It was of course verified at the end of these experiments that no accidental fixation of the $P$ allele had occurred in the Andasibé strain while it was kept in the laboratory.

It is assumed that in other African populations a comparable system is also effective, responsible for the very low transmission by males observed in all the populations examined and very different from that prevailing in European populations (Fleuriet, 1986)

It seemed of interest to determine whether this restriction of transmission was specifically directed against viral clones perpetuated in these populations or whether any viral genotype would be affected. The purpose of Experiment 3 was to try to answer this question.

\section{Experiment 3}

This experiment was aimed at determining whether the host genetic mechanism lowering viral transmission by males in the Andasibé population was effective on any viral clone or on the Andasibé virus only. For this purpose 7 viral clones were chosen, differing in their genetic characteristics (eg Ménétréol and Biziat; Fleuriet, 1990 ) or their geographic origin (France, USA); some were of viral type I, eg the Andasibé virus, others of viral type II. All were transferred by maternal transmission into flies of Andasibé genotype (chromosome 4 was not controlled), and valence of males measured. The original genotype was then reconstituted in each line and valence of males measured again, to check any possible variation of viral genotype (see protocol in figure 5). As a control, the same process was used with the Andasibé infected line in order to ensure that the genetic effect detected in Experiment 2 was still effective after $2 \mathrm{yr}$ in the laboratory. In this case, the genotype reconstituted in the line at generation 5 was the $B_{2^{\prime}}$ genotype, which in Experiment 2 was shown not to impair transmission of the Andasibé virus. Results are presented in figure 6 . 


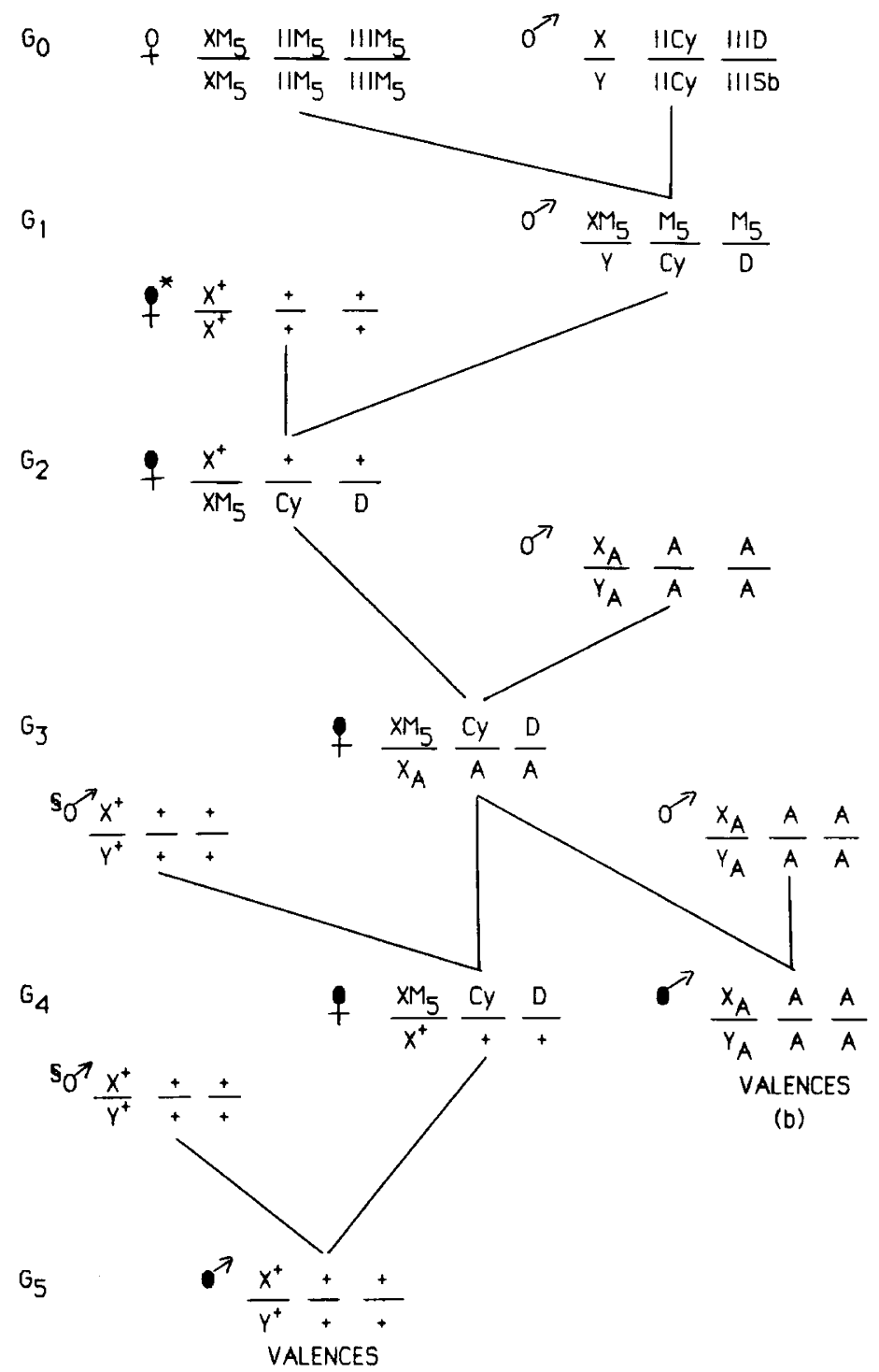

(c)

Fig 5. Protocol used in Experiment 3 (the same protocol was used for each of the 8 infected lines examined); symbols as in figure 1, A: chromosomes originating in the Andasibé sample. In the experiment analyzing the Andasibé infected line, the genotype reconstituted at generation 5 was the $B_{2^{\prime}}$ genotype. For this purpose, the males used at generations 3 and $4(\xi)$ were $B_{2^{\prime}}$ males and not + males. Three measurements of valences were performed (see figure 6 ). Graph $a$ : valences in the original genotype (in this experiment the values presented were not measured immediately before the experiment as in Experiments 1 and 2, but were the measurements made when the samples had just been collected, 2 yr before for the Andasibé line, 10 months before for the other 7 lines). Graph $b$ : valences of A males (reconstituted Andasibé genotype) carrying the viral clone tested. Graph $c$ : valences of males, carrying the viral clone tested and with reconstituted original genotype (or $B_{2}$ reconstituted genotype for Andasibé line). 

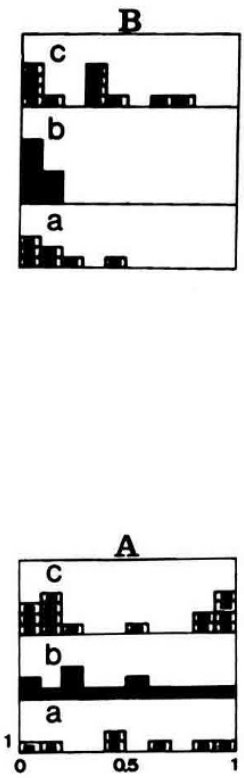
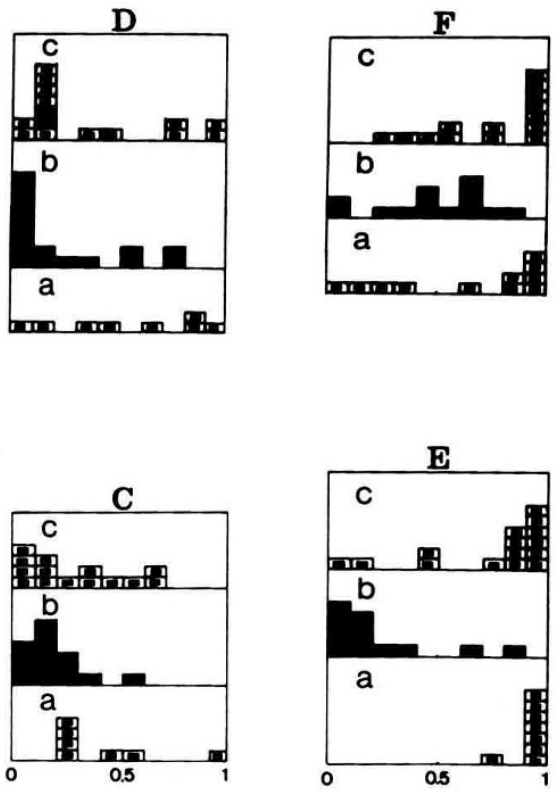

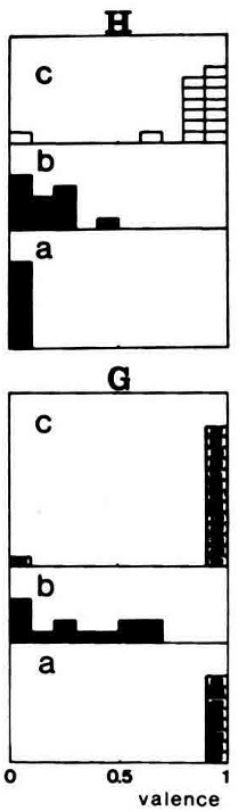

Fig 6. Measurement of valences in Experiment 3 ( 8 infected lines); see protocol in figure 5 . Graph $a$ (black dots): valences of males in the original line. Graph $b$ (black): valences of $G_{4}$ males carrying the viral clone tested. Graph $c$ (black dots): valences of $G_{5}$ males carrying the viral clone tested. For Andasibé line (H): Graph $a$ (black): valences in the original line. Graph $b$ (black): valences of $G_{4}$ males (reconstituted original Andasibé genotype) carrying the Andasibé viral clone. Graph $c$ (white): valences of $G_{5}$ males (reconstituted $B_{2}$ ' genotype) carrying the Andasibé viral clone. Origin of the 8 infected lines examined (see Materials and Methods): A: Biziat 2; B: Biziat 9; C: Biziat 11; D: Ménétréol 10; E: Ménétréol 19; F: Gilroy 7; G: Gilroy 20; H: Andasibé.

The measurements made on the Andasibé line (graph $7 \mathrm{H}$ ) show that the genetic determinism of restriction was still present in the Andasibé genotype (compare graphs $b$ and $c$ ) even if it was somewhat less efficient than originally (graphs $a$ and $b)$. This difference shows that fly and/or virus genotypes evolved slightly in the laboratory since their collection $2 \mathrm{yr}$ before.

Of the 7 lines examined, 4 were almost unaffected by the Andasibé genotype ( $\mathrm{A}$, B, C, D). All had been collected in France; among them, one was type I (C), the other 3 were type II. A strong effect was observed on the $E$ viral clone. It was a viral type II, from the same population (Ménétréol) as the $D$ viral clone.

Some effect was observed on the 2 lines from the same American population (Gilroy), both of viral type I: a weak effect on the $F$ clone, but a very strong one on the $G$ clone. The effect was thus not specific to the viral type (I or II) nor to the geographic origin.

The hypothesis of a multigenic determinism of the Andasibé restriction of transmission might be favoured by the fact that no segregation was observed after 
$2 \mathrm{yr}$ in the laboratory. But one cannot exclude the possibility, if only one locus is involved, of fixation of the allele for resistance in the Andasibe strain.

It thus appears from this experiment that in populations of various geographic origins, some viral clones can be found which are sensitive to the genetic restriction present in the Andasibé population. They might be in the minority ( 2 clones as strongly affected as in the original population, out of 7 examined). They can coexist, as another example of the viral polymorphism, with viral clones resistant to that fly genotype (as observed in the Ménétréol population). A parallel might be established with the situation at the $\operatorname{ref}(2) P$ locus: 2 viral types, one very sensitive to the $P$ allele (type I) the other more resistant (type II), coexist in populations in presence of the $P$ allele (Fleuriet, 1988). The difference is that in the population (Ménétréol) where the 2 types of clones have been found, there is no indication that the Andasibé alleles(s) might be found (and this observation is another example of mutation randomness). Conversely, in the African populations where these restriction alleles are found, no indication of a viral polymorphism has as yet been observed.

The interesting point is that viral clones resistant to these alleles can thus be found in wild populations, but none has yet been collected in Africa. This might be interpreted as a local coadaptation of both partners, the virus and the fly; it would lead to a low frequency of infected flies in these populations where for unknown reasons, the $P$ allele frequency is very low (Fleuriet, 1986). A similar effect, preventing the virus from invading host populations thus appears to take place in European (Fleuriet, 1988) and African populations through different mechanisms. It may be assumed that other such systems of coadapted genotypes would be found in samples collected around the world.

\section{ACKNOWLEDGMENTS}

I would like to thank F Ayala, J David and D Sperlich for collecting flies and JC Bregliano for critically reading the manuscript. This work was supported by grants from the Centre National de la Recherche Scientifique (UA 360, GRECO 44) and the Fondation pour la Recherche Médicale Française.

\section{REFERENCES}

Carton Y (1986) La coévolution. Biologie des populations. Coll Nat CNRS 18-24 David J (1959) Etude quantitative du développement de la drosophile élevée en milieu axénique. Bull Soc Biol Fr Belg 93, 472-505

Fleuriet A (1980) Polymorphism of the hereditary sigma virus in natural populations of $D$ melanogaster. Genetics $95,459-465$

Fleuriet A (1986) Perpetuation of the hereditary sigma virus in populations of its host, $D$ melanogaster. Geographical analysis of correlated polymorphisms. Genetica $80,167-177$

Fleuriet A (1988) Maintenance of a hereditary virus: the sigma virus in populations of its host D melanogaster. In: Evol Biol (Hecht M, Wallace B, eds) Plenum Publishing Corp 23, 1-30

Fleuriet A (1990) Evolution of natural populations in the $D$ melanogaster - sigma virus system II. Northern and central France. Genetica 81, 33-41 
Fleuriet A, Periquet G, Anxolabehere D (1990) Evolution of natural populations in the $D$ melanogaster - sigma virus system I. Languedoc. Genetica 81, 21-31 Gay P (1978) Les gènes de la drosophile qui interviennent dans la multiplication du virus sigma. Mol Gen Genet 159, 269-283

Hardy JL, Houk EJ, Kramer LD, Reeves WC (1983) Intrinsic factors affecting vector competence of mosquitoes for arboviruses. Ann Rev Entomol 28, 229-262 Plus N (1954) Etude de la multiplication du virus de la sensibilité au gaz carbonique chez la drosophile. Bull Soc Biol Fr Belg 88, 1-46 